\title{
Shifting Gears for the Use of the Shifting Baseline Syndrome in Ecological Restoration
}

\author{
Matías Guerrero-Gatica ${ }^{1, *}$, Enrique Aliste ${ }^{2}$ (i) and Javier A. Simonetti ${ }^{1}$ \\ 1 Facultad de Ciencias, Universidad de Chile, Casilla 653, Santiago 7800003, Chile; jsimonet@uchile.cl \\ 2 Departamento de Geografía, Universidad de Chile, Casilla 3387, Santiago 8331051, Chile; \\ ealiste@uchilefau.cl \\ * Correspondence: mguerrerog@ug.uchile.cl
}

Received: 25 January 2019; Accepted: 5 March 2019; Published: 9 March 2019

\begin{abstract}
There are two barriers to accomplishing restoration of ecosystems: insufficient information about historical baselines to guide restoration, and shifts between the actual baselines and perceptions about historical conditions. These two conditions generate a phenomenon called shifting baseline syndrome (SBS). Our study systematically reviewed and quantitatively analyzed the SBS studies. There is an increase and subsequent stabilization in the number of publications, $32 \%$ of scientific articles added new information and $5 \%$ of them delivered biological and social information required to demonstrate the SBS presence. Meta-analysis conducted showed an inconsistency between biological and social data. The inclusion of a greater amount of species in the biological data compared to social data produced the inconsistency. There must be an improvement in reporting both biological and social information to assess SBS. The integration of both sources of information would also enhance the success of restoration projects. The consideration of perceptions about resource users are also in accordance with global agreements about sustainable use of natural resources and ecological restoration.
\end{abstract}

Keywords: ecological restoration; environmental assessment; environmental perceptions; historical ecology; meta-analysis; biodiversity conservation

\section{Introduction}

One of the challenge faced by humanity to achieve sustainability is to recover ecosystems damaged historically through ecological restoration [1]. To do it, a key issue for the actions taken to restore an ecosystem is to assess a target to aim at, which should represent the original or historical environmental condition or ecosystem functions prior to a perturbation. The setting of such a baseline is complex because of at least two factors: first, if there are gaps of historical data field-based assessments, information must rely on indirect sources, many of them scattered and difficult to compile. For example, paintings, historical documents, and narratives have been used for evaluating temporal changes in environmental conditions [2,3]. The reliance on these qualitative sources leads to the second issue, the changes in individual or collective perceptions regarding what conditions characterize an ecosystem prior to a perturbation. These two factors combined produce a phenomenon described as shifting baseline syndrome (SBS; Figure 1). Thus, the shifting baseline syndrome is defined as a downward shift in perceptions or expectations of an environmental baseline as a consequence of a biological change [2,4] (Figure 1). The SBS could be either through personal or generational amnesia, i.e., a change in perceptions experienced by a person in their own life or a change in perceptions among generations [5]. According to Papworth et al. (2009) [5], two conditions must exist to demonstrate the existence of an SBS: a biological change must be present and a concomitant change in environmental perceptions must occur, either age or experience-related (Figure 1). 


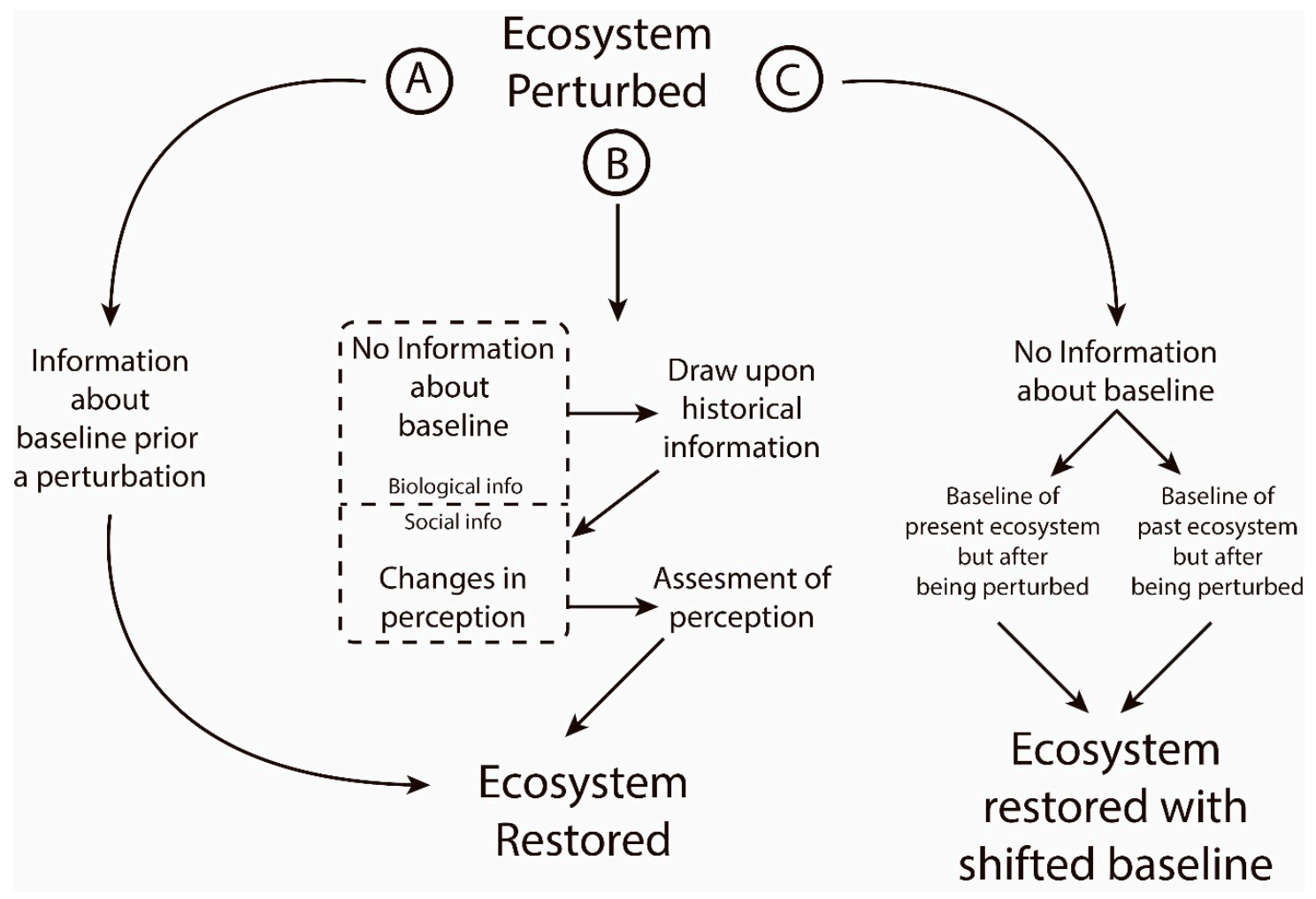

Figure 1. Three pathways of restoration and subsequent steps to decide a reference condition. In (A) there is an ideal scenario where information about a baseline prior a perturbation is available; in (B) no information about a baseline is present, using both biological and social data to restore an ecosystem; in (C) shifting baseline syndrome (SBS) is occurring, producing an ecosystem with a shifted baseline.

Recognizing the presence of SBS has critical implications for restoration projects which, at the same time, will impact conservation actions and sustainability of ecosystems [6]. Thus, when there is information about ecosystem baselines prior to a perturbation, the restoration targets can be recognized, avoiding impoverished conservation status (Figure 1). Therefore, avoiding the effects of SBS, that is, misunderstand ecosystem baselines prior to a perturbation, will ultimately imperil the success of ecological restoration for two reasons: first, the actions will address a transformed target to restore (e.g., [7]) and second, the projects can overlook a mismatch between restoration goals and resource user's perceptions about that restoration goal. Concerning the first one, for example, declined populations can be considered as populations in an adequate conservation status by resource users and decision-takers, generating a failed template for restoration projects. When there is no documentation of these modifications, ecosystems may be led to an impoverished state since there is no target based on environmental states prior to a perturbation to restore the ecosystem of interest, provoking a SBS. This ultimately generates ecosystems characterized by the accumulation of a long history of use and anthropogenic transformations [8-11]. According to the above mentioned, a better documentation of SBS about biological changes and the subsequent lack of awareness about prior ecosystem status will allow scientists to design more efficient restoration programs. The documentation of resource user's perceptions will provide information in order to both recognize the presence or absence of SBS and generate support for restoration and conservation measures [12-14].

Concerning the second reason, that is, the projects can overlook a mismatch between restoration goals and resource user's perceptions about that restoration goal [15], if not well-identified, the mismatch can generate a conflict among the scientists/technicians and resource users, reducing the restoration success. For example, Wu et al. (2009) [14] report the inefficacy in restoring ponderosa pine forests in California, USA, due to the difference between people's perceptions and restoration practitioners about the ecosystem restored, which, from an ecological perspective, implies a decrease 
in ponderosa pine density. Therefore, recognizing SBS can give us evidence about both the biological change and the social perceptions of that environmental change, contributing to the achievements of restoration goals $[14,16]$.

After more than 20 years of the SBS concept emergence, while some studies have reviewed the issue [17], no quantitative analysis has been made about the literature that has considered the phenomenon. There is an urgent need to evaluate the extent of the phenomenon. Additionally, while we understand that the issue deserves many descriptions and concepts to refer to it, the analysis has a methodological facility to work with a specific definition, facilitating the subsequent literature research. Thus, the present study reviewed the scientific literature that emerged about SBS with the objective to evaluate the amount of studies and how those studies have tackled the issue to evaluate its presence to, ultimately, avoid it. To do it, a meta-analysis was conducted in order to assess quantitatively the components of SBS: abundance measured (hereafter biological data), which corresponds to information calculated by scientific or technical groups; and one for abundance perceived (hereafter social data), which corresponds to information obtained from resource users (e.g., fishers, game hunters among others). The meta-analysis as a conservation tool has been recognized to support better conservation decisions [18]. In our study, the meta-analysis represent a useful tool to evaluate the quantitative information of both biological and social data presented in SBS studies. If a SBS phenomenon is occurring, a change should have happened in the ecosystem with lack of awareness about that changes. Ultimately, the meta-analysis can show the trends of biological and social information that emerged from these studies, intending to improve the success of restoration projects.

To accomplish our objective, first we systematically reviewed the literature following the conditions developed by Papworth et al. (2009) [5] to recognize the presence of SBS. Additionally, we analyzed the main trends of literature published to characterize research about SBS. Second, through a meta-analysis, we assessed quantitatively the evidence emerged from biological data, i.e., information that was taken the field and; social data, i.e., information recorded about people's perceptions of environmental conditions. If changes at the global scale in the environment have been reported [19-21], then, we expect a biological change showed in the meta-analysis, which represents a basic condition for the presence of SBS. We also expect a concomitant perception of those changes by local communities evidenced in the meta-analysis.

\section{Methods}

In order to identify the main trends of publications related to SBS to then conduct a quantitative analysis through a meta-analysis to those studies that showed biological and social information, we conducted a review of the literature published. To do it, the literature search was composed of three phases. In the first phase, we systematically reviewed the scientific literature. The online platform Web of Knowledge was used using the advanced search through the code, TS = " shifting" AND "baseline*"). The search was conducted in three periods: December 2016; December 2017; and December 2018 and encompasses all the literature since the emergence of the concept of SBS (year 1995 to December 2018). A second phase consisted in filtering the publications that were related to the topic of research. Two criteria were used to include them into the review: (1) the publications cited Pauly (1995) [2] and/or Sheppard (1995) [3] or (2) the publication mentioned explicitly the concept of "shifting baseline syndrome", acknowledging, at least, its importance in restoration or conservation issues. Once selected, the third phase consisted in grouping the studies according to their approach for the topic. Three groups were formed: (1) scientific articles that only mentioned the concept without engaging in new empirical analysis; (2) scientific articles that mentioned the issue and added new data of biological or social information (e.g., peoples' perception) to evaluate environmental changes; and (3) scientific articles that showed both biological and social measurements of the species or ecosystem studied, being able to analyze them quantitatively through a meta-analysis. 
Concerning scientific articles that added new data, that is, scientific articles that fulfill the point (2), we analyzed their temporal trends to see the amount of scientific production. We also analyzed the main ecosystems and biomes studied, and taxa that were considered in the studies to see if there is a taxonomic bias in the description of the phenomenon.

The scientific articles that fulfilled the point (3) above mentioned were submitted to the meta-analysis. Only studies reporting mean and standard deviation of field data about the two dimensions (biological and social data) were included in the meta-analysis using Hedge's unbiased standardized mean difference [22,23], which is a measure of the difference between the group means using averages and measures of variance (generally mean and standard deviation). Specifically, two meta-analyses were conducted: one meta-analysis to analyze information about changes in abundance of species and the second one to analyze the information about changes in perceptions of resource users. Hence, two information dimensions were extracted from the studies: biological data and social data. In biological data, we compared two different time span: oldest and most recent data, reconstructing it from available information in each paper or from studies cited by the study. Engauge Digitizer v. 4.1 [24] was used to recover information from graphs presented in the studies if necessary. Abundance or relative abundance, biomass, landings, capture per unit effort or some proxy of the abundance were included. Additionally, biological data was grouped by ecosystem (aquatic and terrestrial), and time of data set (more than 30 years and less than 30 years as a reference of a human generation time; [25]). In social data, we compared two different categories: abundance reported by older users (older data) and by younger users (recent data). Best day's catch, largest individual caught, capture per unit efforts, or some index of abundance were included (such as sites depleted or new target species). Here we only analyzed the overall effect, without grouping data.

Confidence intervals of effect sizes were estimated and their variance by bootstrapping (4999 iterations); P-values were estimated using a randomized effect categorical model as we cannot assume there is one true effect size shared by all studies, with categorical variables (in the case of biological data) or without it (in the case of social data). Heterogeneity of effect sizes was tested through Q-statistics [23]. The null hypothesis is that all effect sizes are equal. Thereby, the test is comparable to ANOVA, in which a significant $Q$ statistic indicates that the variance among effect sizes is greater than expected by sampling error [23]. We conducted a test for publication bias through Spearman rank and Rosenthal's fail-safe number method [26], which, according to Harrison et al. (2011) [27] represents the number of unpublished studies or hidden studies with an effect size of zero that would have to exist in order to make our significan result likely to be due to sampling error rather than any real effect of the experimental treatment. The more common bias in journals is the selection of publication that have significant differences, causing a deficit of studies with non-significant differences.

Significant differences in the meta-analysis were detected when the effect sizes were positive or negative and at the same time, the $\pm 95 \%$ CI does not include the 0 value. Meta-analysis and related tests were conducted using the meta-analytic program MetaWin 2.0 [23].

\section{Results}

Since the term was coined, there has been a steady increase in the number of scientific articles related to SBS. We found 152 publications between 1995 and 2017, with a peak of 20 publications in 2012 and 2014. Of the 152 studies, 82\% (124 publications) deal with aquatic environment and 28\% (42 publications) with terrestrial ecosystems (Figure 2; see Table S1 in Supplementary Materials for full listing of retrieved articles). It is worth noting that 12 publications dealt with both aquatic and terrestrial ecosystems. Thirty-two percent of publications (48 publications) added new data to test the presence of SBS, through measuring the perception of people regarding a biological resource or adding new empirical testing about the resource or resources studied (Table S1). 


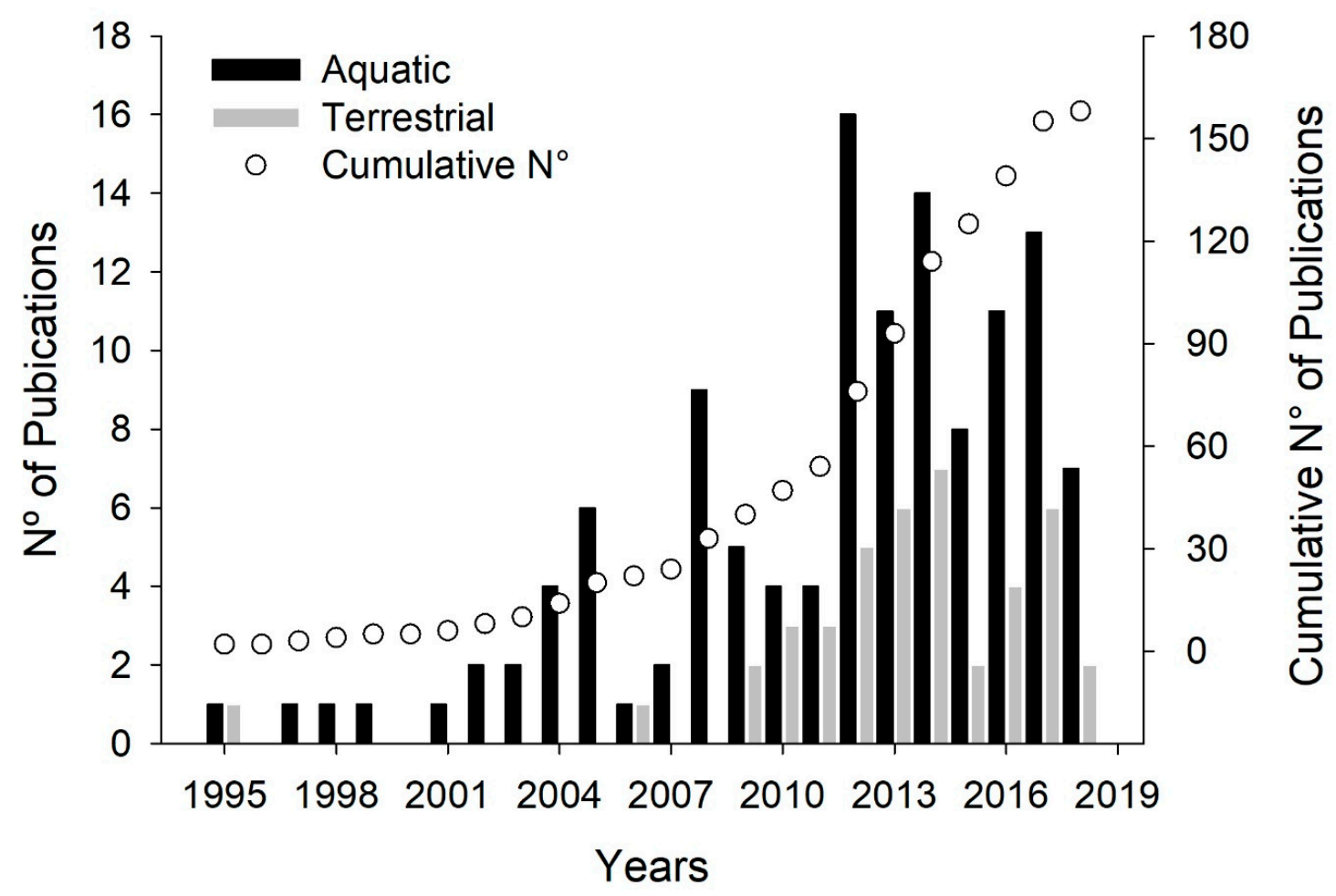

Figure 2. Trend of scientific publications referring to the shifting baseline syndrome. Left axis: number of publications in aquatic ecosystems (black bars) and terrestrial ecosystems (gray bars); right axis: cumulative number of publications (points).

When we analyzed only the publications that added new data in aquatic ecosystems, we found that coastal ecosystem ( 35 publications) was the most frequently analyzed aquatic biome, followed by coral reefs (19 publications), open ocean (12 publications), and freshwater ecosystems (8 publications). In terrestrial ecosystems, studies were performed primarily in tropical forests (8 publications), temperate forests (7 publications), mediterranean vegetation (7 publications), temperate grasslands (3 publications), and boreal forests (3 publications).

In the same way, by analyzing publications that added new data in terms of taxon studied, aquatic vertebrates, mainly bony fishes (41 publications), were the most frequently studied taxon, followed by aquatic invertebrates ( 22 publications), aquatic mammals ( 7 publications), and aquatic reptiles (5 publications). In terrestrial ecosystems, plants were studied by 10 publications, mammals were studied by eight publications, birds were studied by five publications, and vertebrates in general (specifically game animals) were studied by one publication.

For the meta-analysis conducted, only 5\% (8 publications) offer empirical evaluation of species abundances, both reporting biological and social data (Table S1); seven publications from aquatic and one from a terrestrial environment. Five of these eight articles covered less than or equal to a 30-year period and three spanned over more than 30 years. For the meta-analysis carried out for biological data, we did not find publication bias $\left(\mathrm{r}_{\mathrm{s}}=-0.642 ; p=0.086\right)$ and the Rosenthal's safe number (i.e., the number of additional negative publications needed to change results of the meta-analysis from significant to non-significant results) was $25.5[19,20]$. There were no significant differences in the assessed abundance for the overall effect size, because the effect size included the 0 value (Figure 3), but there was significant heterogeneity between the overall studies analyzed $\left(\mathrm{Q}_{\text {between }}=22.43 ; p=0.002\right)$. Further, there were no significant differences between years of data $\left(\mathrm{Q}_{\text {between }}=0.038 ; p=0.916\right)$. 


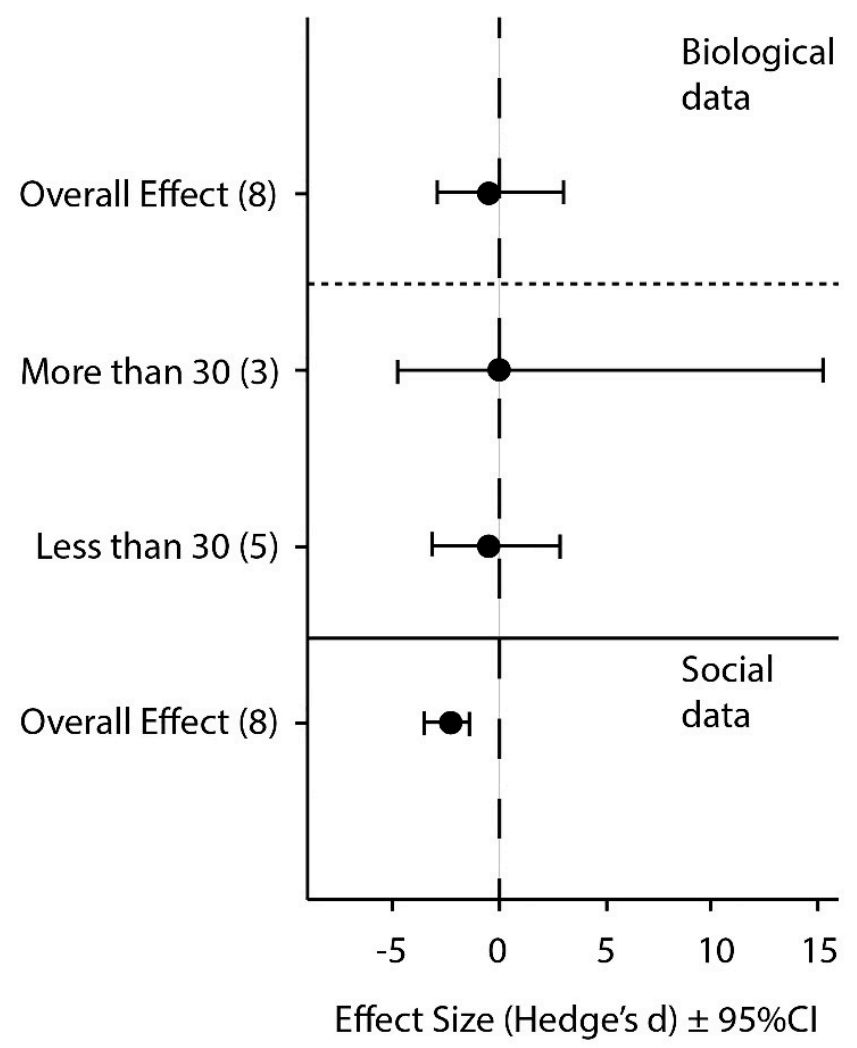

Figure 3. Hedge's d mean effect sizes $\pm 95 \% \mathrm{CI}$ of biological data, depending on the temporal data (more than 30 years and less than 30 years of information) or the overall effect; and social data overall effect. Number in brackets represent number of scientific articles included in each analysis. Dashed line represent the 0 value and when the effect size include the 0 value, there is no significant differences.

Regarding social data, the same eight publications were analyzed. There was no publication bias $\left(\mathrm{r}_{\mathrm{s}}=-0.55 ; p=0.125\right)$ and Rosenthal's fail-safe numbers was high compared to sample size (783.7), suggesting that the data were robust. There was no significant heterogeneity $\left(Q_{\text {between }}=8.41 ; p=0.39\right)$ but analysis of studies with social data suggest a significant decline from baseline conditions (Figure 3).

\section{Discussion}

Despite its relevance for policy and practice, the reported empirical evidence for SBS has been relatively weak. To demonstrate the existence of a SBS, a biological change must be present and a concomitant change in environmental perceptions must occur, either age or experience-related [5]. Studies that mention the issue increased during the last 20 years, but there is a paucity of studies that effectively included empirical testing, consequently, there is poor information identifying contexts in which SBS has occurred.

\subsection{Analysis of Scientific Papers about SBS}

The trend in publications that took into account the phenomenon, assessed by the number of publications that cited SBS through time (Figure 2) increased until 2013. By analyzing the scientifc articles that added new empirical data (group 2 of the Table S1), there is a bias toward aquatic ecosystems compared to terrestrial ecosystems. The bias is also repeated in publications analyzed by the meta-anlysis (group 3 of the Table S1). One of the explanations is the empirical background of the concept, since it is a phenomenon firstly described in aquatic ecosystems. The need to extrapolate the phenomenon to different aquatic environments could create the bias toward more publications in this ecosystem. In a scenario where many terrestrial ecosystems are threatened by human-induced 
drivers [28], there is a challenge to increase the number of publications in these ecosystems and avoid their biodiversity loss $[17,29]$.

Most publications that added new empirical data did not deliver appropiate information about the state of the resource (biological data), precluding a comparison between abundance measured through resource users and abundance measured by researchers. Notwithstanding that already mentioned, we also acknowledged the limited availability of historical biological data about baselines in many ecosystems. To overcome that, several studies based their information in perceptions of resource users. The information gathered through perceptions would support subsequent decisions about the resources assessed and will fill part of the information gap that scientists and technical groups have not studied.

We recognize the benefits that the measurement of people's perceptions can add into conservation and resource management (e.g., [30]). Nevertheless, in the case where possible, it is imperative to include both biological and social data. These criteria will reinforce the empirical basis reporting SBS and baselines to then, generate stronger evidence-based restoration programs and ameliorate the efficacy of restoration goals.

The phenomenon of SBS is becoming an important issue in conservation due to its effects in terms of conservation of biodiversity, even at global scales [31] and sometimes is occurring undetected [32]. Its importance has been translated to the increase in publications about SBS along time (Figure 2). One possible explanation is the recognition that SBS, through the measurements of perception that resource users have about their environment, would improve the efficacy of restoration and conservation actions [33-37].

In proportion to the total amount of publications found, the number of studies showing evidence to demonstrate the presence of a SBS (group 3 of the Table S1) was low (only 5\% of publications), revealing a reduced amount of publications that are evaluating the issue. Intriguingly, this group of publications showed that biological data of the resource base depicted no significant difference. However, results from social data showed a significant reduction in its availability (Figure 3). The inconsistency among biological data and social data might have two explanations: (a) resource users are more sensitive to changes that, albeit non-significant statistically, are sufficient to modify time-energy investment among users or; (b) biological data acquired might not be tested correctly.

To overcome the inconsistency, studies must analyze abundance changes by a comparison of biological and social data about the same species considered. By contrast, some studies measured a range of species different than the focal species from which studies evaluate perceptions (e.g., [5,10,12,38-40]; but see [41] for an assessment of the same group of species which measured biological and social data of the same group of species). These studies were analyzed through the meta-analysis since they presented biological data of a group of species while, at the same time, evaluate perceptions of resource users of other group of species to assure the presence of SBS. Thus, our meta-analysis results about the inconsistency of biological data and social data support the explanation (b). As a consequence, if studies were not using a direct measure of abundance that correspond to social data, there will be an inaccurate assessment of species abundance, impeding the detection of species abundance decline (or detectability by resource-users).

Progress must be carried out toward measuring biological and social data about abundances of the same ensemble of species, improving the information regarding on the target baseline. If the evidence about the presence of SBS is poor, this does not mean that we must discount the gap among the baseline prior to the perturbation and the baseline updated. What we see through our study is that we acknowledge a contribution of resource user's perceptions in order to complement biological data and then avoid a biased resetting of the baseline.

Failure in the recognition of adequate baselines due to the presence of SBS might lead to mismanaging landscapes for restoration and conservation purposes. On the opposite side, the incorporation of evaluating SBS will impact into more efficient restoration actions that will ultimately impact in the conservation status of ecosystems and biodiversity [29]. An important 
point is that disagreements between biological and social data may be occur, which could lead to a mismatch between people's expectations and conservation goals when an environment is restored [14]. The mismatch between biological and social information may happen even at the scenario where the people's expectations are above the restoration actions. In these scenarios it is critical to use the reference conditions as a guide, not as a straitjacket [42].

When we analyzed restoration variables of scientific publications, we recognize that there are limitations in terms of evaluating only abundance emerged from biological or social sudies as a variable response. This is explained in part because the history of the concept comes from fishery science, which has evaluated the presence (or not) of the phenomenon through measuring abundances or stocks of individuals. Later studies mainly encompassed measurements of this variable. Progress must be carried out toward integrating more complex ecological variables (e.g., species richness, functional diversity, ecosystem strcuture, among others) in order to detect, prevent, or reverse the advance of the phenomenon and enhance the quality of restoration projects.

The possibility that SBS can be present in an ecosystem to be restored obligates to the restoration practitioners to analyze the restoration actions from a historical perspective. However, this is also dependent on the objectives that the restoration actions can have. For example, some restoration actions have the goal to restore ecosystem functions lost by an extinct species, replacing those species with exotic ones that have similar ecosystem functions [43].

The historical perspective is also challenged by the climate change scenario [42]. By that, the restoration actions must be aware about the future climatic trends and how this historical condition must be achievable in a possible different regional or local climatic range. In this context, the historical conditions can be used as a guideline and not as the final goal of the actions taken to restore an ecosystem.

\subsection{SBS and the Incorporation of Human Dimensions}

SBS brings out the discussion around the decision-making process of restoration projects that include social perspectives [5,44]. Studies addressing the evaluation of SBS for restoration purposes can also serve as spearhead to increase the consideration of social dynamics and subsequent environmental outcomes resulting from conservation initiatives [45,46]. Thus, the study and assessment of the SBS can act as a fertile field to incorporate human dimensions into projects aimed at restoring and conserving ecosystems.

The restoration of an ecosystem thus represents a challenge due to potential social barriers for carrying out those actions. Therefore, while historical information about ecosystems can be present, they can be difficult to recreate [42], mainly because of generational amnesia (e.g., [14]). For example, in Chile, pine exotic plantations (e.g., Pinus radiata) are now an important exotic and novel land cover for pulp production [47,48], representing aproximately 1.5 millions hectares [47]. Despite the availability of information about past environmental baselines (biological data) [49], there is no consensus among Chilean citizens regarding pine plantations as a threat to biodiversity (social data) in case restoration from exotic plantation to native forests ought to be carried out [50]. The challenge is to accomplish both the restoration objectives emerging from biological data as well as people's expectations (social data) about what is the adequate baseline if we want to restore native forests from exotic plantations.

A way forward is to enhance interdisciplinary approaches, aiming to agree on a state or configuration of the ecosystem to restore [51,52]. A key step is to adjust studies toward target-focused cooperation instead of focusing on single disciplines, improving the consideration of social-ecological components ignored in previous studies [46,52-54]. This approach might strengthen restoration activities particularly when local knowledge is equal to or more accurate than the technical analysis (as most do not focus on species assessed by users; [55,56]). A more critical issue is that the incorporation of the human dimension does not sacrifice restoration standards, but it will add a 
social-ecological perspective that might improve the success of further restoration and conservation actions [3,33-37].

At a global scale, the research approach to evaluate the presence of SBS, which incorporates both biological as well as social data, is also in accordance with global agreements related to ecological restoration. For example, the Convention on Biological Diversity (CBD) in 2010 agreed in its 15th Aichi Biodiversity Target that parties should restore at least $15 \%$ of degraded ecosystems by 2020. The fulfillment of the target must be achieved respecting the traditional knowledge of local communities, integrating it, at the same time, in the implementation of the convention. Efforts to assess SBS should change and must be accelerated them to evaluate the phenomenon and offer ways to better calibrate reference targets and subsequent shifts in the ecosystems and associated ecosystem services [42]. The consideration of different sources of information for restoration actions (biological and social data) can also improve the set of indicators to guide those actions. Making more complex the response variables to evaluate the success of restoration projects will help in overcoming the lack of response variables showed in the publications integrated to our study, abundance being the most frequent variable used. Supporting decisions with the approach proposed by the SBS evaluation, and even incorporating "other kinds of knowledge than science" (sensu [57]), would fulfill knowledge gaps about baselines in order to restore ecosystems for conservation and human well-being.

\section{Conclusions}

The SBS is a phenomenon that describes a downward of an environmental baseline as a consequence of a biological change that subsequently generate a change in perceptions of resource users or scientists about what the past environmental conditions were. Since the term was coined by Daniel Pauly in 1995, no evaluation has been done to assess the quantity and quality of studies done. In our study, we systematically reviewed the scientific literature and found 152 publications which, at least, mentioned the phenomenon. Of those publications, only eight of them used quantitative data to evaluate the presence of SBS, which is, reporting biological and social information about the resource evaluated [5]. Considering our results of the review and the quantitative analysis through a meta-analysis conducted, we recognize that there must be an improvement in the reporting of SBS which consider both the assessment of biological and social data. Additionally, there is a potential to use resource user's perceptions to complement the information gap about the baseline prior to a perturbation, improving at the same time the successful of those restoration projects. The potential use of resource user's perceptions and other local stakeholders is in accordance with global agreements that mandates the integration of local knowledge to restore ecosystems for the year 2020.

Supplementary Materials: The following are available online at http:/ /www.mdpi.com/2071-1050/11/5/1458/ s1.

Author Contributions: M.G.-G., E.A., J.A.S. conceived and designed the research; M.G.-G. performed the analysis; M.G.-G., E.A., J.S.S. analyzed data; M.G.-G., E.A., J.A.S. contributed analysis tools; M.G.-G., E.A., J.A.S. wrote and edited the manuscript.

Funding: This work has been supported by National Chilean Agency for Scientific Research (CONICYT), Projects Fondecyt 1150770 and PIA-Anillo Soc 1404. Partial support from Fondecyt 1140657 is also appreciated.

Acknowledgments: We are grateful to Meredith Root-Bernstein for her suggestions to improve the manuscript and English corrections and Tomas Poch and María Belén Gallardo for their valuable comments.

Conflicts of Interest: The authors declare no conflicts of interest.

\section{References}

1. Urbanska, K.M.; Webb, N.R.; Edward, P.J. Why restoration. In Restoration Ecology and Sustainable Development; Urbanska, K.M., Webb, N.R., Edward, P.J., Eds.; Cambridge University Press: Cambridge, UK, 2000; pp. 3-7.

2. Pauly, D. Anecdotes and the Shifting Baseline Syndrome of Fisheries. Trends Ecol. Evol. 1995, 10, 430. [CrossRef]

3. Sheppard, C. The shifting baseline syndrome. Mar. Pollut. Bull. 1995, 30, 706. [CrossRef] 
4. Turvey, S.T.; Barrett, L.A.; Yujiang, H.; Lei, Z.; Xinqiao, Z.; Xianyan, W.; Yadong, H.; Kaiya, Z.; Hart, T.; Ding, W. Rapidly shifting baselines in Yangtze Fishing Communities and Local Memory od Extinct Species. Conserv. Biol. 2010, 24, 778-787. [CrossRef] [PubMed]

5. Papworth, S.K.; Rist, J.; Coad, L.; Milner-Gulland, E.J. Evidence for shifting baseline syndrome in conservation. Conserv. Lett. 2009, 2, 93-100. [CrossRef]

6. Choi, Y.D.; Temperton, V.M.; Allen, E.B.; Grootjans, A.P.; Halassy, M.; Hobbs, R.J.; Naeth, M.A.; Torok, K. Ecological restoration for future sustainability in a changing environment. Ecoscience 2008, 15, 53-64. [CrossRef]

7. Jacakson, J.B.C. Reefs since Columbus. Coral Reefs 1997, 16, S23-S32. [CrossRef]

8. Lotze, H.; Milewski, I. Two centuries of multiple human impacts and successive changes in a North Atlantic food web. J. Ecol. Soc. Am. 2004, 14, 1428-1447. [CrossRef]

9. Worm, B.; Barbier, E.B.; Beaumont, N.; Duffy, J.E.; Folke, C.; Halpern, B.S.; Jackson, J.B.C.; Lotze, H.K.; Micheli, F.; Palumbi, S.R.; et al. Impacts of biodiversity loss on ocean ecosystem services. Science 2006, 314, 787-790. [CrossRef]

10. Connell, S.D.; Russell, B.D.; Turner, D.J.; Shepherd, S.A.; Kildea, T.; Miller, D.; Airoldi, L.; Cheshire, A. Recovering a lost baseline: Missing kelp forests from a metropolitan coast. Mar. Ecol. Prog. Ser. 2008, 360, 63-72. [CrossRef]

11. Roff, G.; Clark, T.R.; Reymond, C.E.; Zhao, J.-X.; Feng, Y.; McCook, L.J.; Done, T.J.; Pandolfi, J.M. Palaeoecological evidence of a historical collapse of corals at Pelorus Island, inshore Great Barrier Reef, following European settlement. Proc. R. Soc. B Biol. Sci. 2012, 280, 20122100. [CrossRef]

12. Sáenz-Arroyo, A.; Roberts, C.M.; Torres, J.; Cariño-Olvera, M. Using fishers' anecdotes, naturalists'observations and grey literature to reassess marine species at risk: The case of the Gulf grouper in the Gulf of California, mexico. Fish Fish. 2005, 6, 121-133. [CrossRef]

13. Ainsworth, C.H.; Pitcher, T.J.; Rotinsulu, C. Evidence of fishery depletions and shifting cognitive baselines in Eastern Indonesia. Biol. Conserv. 2008, 141, 848-859. [CrossRef]

14. Wu, T.; Petriello, M.A.; Kim, Y.S. Shifting baseline syndrome as a barrier to ecological restoration in the American southwest. Ecol. Restor. 2011, 29, 213-215. [CrossRef]

15. Aretano, R.; Petrosillo, I.; Zaccarelli, N.; Semeraro, T.; Zurlini, G. People perception of landscape change effects on ecosystem services in small Mediterranean islands: A combination of subjective and objective assessments. Landsc. Urban Plan. 2013, 112, 63-73. [CrossRef]

16. Ulman, A.; Pauly, D. Making history count: The shifting baselines of Turkish fisheries. Fish. Res. 2016, 183, 74-79. [CrossRef]

17. Soga, M.; Gaston, K.J. Shifting baseline syndrome: Causes, consequences, and implications. Front. Ecol. Environ. 2018, 16, 222-230. [CrossRef]

18. Koricheva, J.; Gurevitch, J.; Mengersen, K. Handbook of Meta-Analysis in Ecology and Evolution; Princeton University Press: Princeton, NJ, USA; Oxford, UK, 2013; ISBN 9780691137285.

19. Walther, G.-R.; Post, E.; Convey, P.; Menzel, A.; Parmesan, C.; Beebee, T.J.C.; Fromentin, J.-M.; Hoegh-Guldberg, O.; Bairlein, F. Ecological responses to recent climate change. Nature 2002, 416, 389-395. [CrossRef]

20. Foley, J.A.; DeFries, R.; Asner, G.P.; Barford, C.; Bonan, G.; Carpenter, S.R.; Chapin, F.S.; Coe, M.T.; Daily, G.C.; Gibbs, H.K.; et al. Global consequences of land use. Science 2005, 309, 570-574. [CrossRef]

21. Halpern, B.S.; Walbridge, S.; Selkoe, K.A.; Kappel, C.V.; Micheli, F.; D'Agrosa, C.; Bruno, J.F.; Casey, K.S.; Ebert, C.; Fox, H.E.; et al. A global map of human impact on marine ecosystems. Science 2008, 319, 948-952. [CrossRef]

22. Rosenthal, R. Meta-Analytic Procedures for Social Research; Sage Publications: London, UK, 1991; Volume 6, ISBN 080394246X.

23. Rosenberg, M.; Adams, D.; Gurevitch, J. Metawin Statistical Software for meta-Analysis; Sinauer Associates, Inc.: Sunderland, MA, USA, 2000; ISBN 0878937609.

24. Mitchell, M.; Muftakhidinov, B.; Winchen, T. Engauge Digitizer Software. A free open-source software to extract data points from a graph image. Available online: markummitchell.github.io/engauge-digitizer/ (accessed on 9 March 2014).

25. Charlesworth, B. Evolution in Age-Structured Populations; Cambridge University Press: Cambridge, UK, 1994; Volume 2. 
26. Gates, S. Review of methodology of quantitative reviews using meta-analysis in ecology. J. Anim. Ecol. 2002, 71, 547-557. [CrossRef]

27. Harrison, F. Getting started with meta-annalysis. Meth. In Ecol. Evol. 2011, 2, 1-10. [CrossRef]

28. Myers, N.; Mittermeier, R.A.; Mittermeier, C.G.; Da Fonseca, G.A.; Kent, J. Biodiversity hotspot for conservation priorities. Nature 2000, 403, 853. [CrossRef] [PubMed]

29. Dobson, A.P.; Bradshaw, A.D.; Baker, A.J.M. Hopes for the future: Restoration ecology and conservation biology. Science 1997, 277, 515-522. [CrossRef]

30. Elwell, T.L.; Gelcich, S.; Gaines, S.D.; López-Carr, D. Using people's perceptions of ecosystem services to guide modeling and management efforts. Sci. Total Environ. 2018, 637-638, 1014-1025. [CrossRef] [PubMed]

31. Santini, L.; González-Suárez, M.; Rondinini, C.; Di Marco, M. Shifting baseline in macroecology? Unravelling the influence of human impact on mammalian body mass. Divers. Distrib. 2017, 23, 640-649. [CrossRef]

32. Buckley, S.M.; Thurstan, R.H.; Tobin, A.; Pandolfi, J.M. Historical spatial reconstruction of a spawning-aggregation fishery. Conserv. Biol. 2017, 31, 1322-1332. [CrossRef] [PubMed]

33. Ormsby, A.; Kaplin, B.A. A framework for understanding community resident perceptions of Masoala National Park, Madagascar. Environ. Conserv. 2005, 32, 156-164. [CrossRef]

34. Allendorf, T.; Swe, K.K.; Oo, T.; Htut, Y.; Aung, M.; Aung, M.; Allendorf, K.; Hayek, L.A.; Leimgruber, P.; Wemmer, C. Community attitudes toward three protected areas in Upper Myanmar (Burma). Environ. Conserv. 2006, 33, 344-352. [CrossRef]

35. Ramakrishnan, P.S. Traditional forest knowledge and sustainable forestry: A north-east India perspective. For. Ecol. Manag. 2007, 249, 91-99. [CrossRef]

36. Balaguer, L.; Escudero, A.; Martín-Duque, J.F.; Mola, I.; Aronson, J. The historical reference in restoration ecology: Re-defining a cornerstone concept. Biol. Conserv. 2014, 176, 12-20. [CrossRef]

37. Bennett, N.J.; Dearden, P. Why local people do not support conservation: Community perceptions of marine protected area livelihood impacts, governance and management in Thailand. Mar. Policy 2014, 44, 107-116. [CrossRef]

38. Bunce, M.; Rodwell, L.D.; Gibb, R.; Mee, L. Shifting baselines in fishers' perceptions of island reef fishery degradation. Ocean Coast. Manag. 2008, 51, 285-302. [CrossRef]

39. Coll, M.; Carreras, M.; Ciércoles, C.; Cornax, M.J.; Gorelli, G.; Morote, E.; Sáez, R. Assessing fishing and marine biodiversity changes using fishers' perceptions: The Spanish Mediterranean and Gulf of Cadiz case study. PLoS ONE 2014, 9, e85670. [CrossRef] [PubMed]

40. Katikiro, R.E. Perceptions on the shifting baseline among coastal fishers of Tanga, Northeast Tanzania. Ocean Coast. Manag. 2014, 91, 23-31. [CrossRef]

41. Godoy, N.; Gelcich, S.; Vásquez, J.A.; Castilla, J.C. Spearfishing to depletion: Evidence from temperate reef fishes in Chile from temperate reef fishes in Chile to Spearfishing depletion. Ecol. Appl. 2013, 20, 1504-1511. [CrossRef]

42. Harris, J.A.; Hobbs, R.J.; Higgs, E.; Aronson, J. Ecological Restoration and Global Climate Change. Restor. Ecol. 2006, 14, 170-176. [CrossRef]

43. Seddon, P.J.; Griffiths, C.J.; Soorae, P.S.; Armstrong, D.P. Reversing defaunation: Restoring species in a changing world. Science 2014, 345, 406-412. [CrossRef] [PubMed]

44. Campbell, L.M.; Gray, N.J.; Hazen, E.L.; Shackeroff, J.M. Beyond baselines: Rethinking priorities for ocean conservation. Ecol. Soc. 2009, 14, 14. [CrossRef]

45. Casagrande, D.G. The Human Component of Urban Wetland Restoration. Restor. Urban Salt Marsh Interdiscip. Approach 1997, 100, 136-150.

46. Miller, B.W.; Caplow, S.C.; Leslie, P.W. Feedbacks between Conservation and Social-Ecological Systems. Conserv. Biol. 2012, 26, 218-227. [CrossRef]

47. Echeverría, C.; Coomes, D.; Salas, J.; Rey-Benayas, J.M.; Lara, A.; Newton, A. Rapid deforestation and fragmentation of Chilean Temperate Forests. Biol. Conserv. 2006, 130, 481-494. [CrossRef]

48. Nahuelhual, L.; Carmona, A.; Lara, A.; Echeverría, C.; González, M.E. Land-cover change to forest plantations: Proximate causes and implications for the landscape in south-central Chile. Landsc. Urban Plan. 2012, 107, 12-20. [CrossRef] 
49. Armesto, J.J.; Manuschevich, D.; Mora, A.; Smith-Ramírez, C.; Rozzi, R.; Abarzúa, A.M.; Marquet, P.A. From the Holocene to the Anthropocene: A historical framework for land cover change in southwestern South America in the past 15,000 years. Land Use Policy 2010, 27, 148-160. [CrossRef]

50. Püschel-Hoeneisen, N.; Simonetti, J.A. Forested habitat preferences by Chilean citizens: Implications for biodiversity conservation in Pinus radiata plantations. Rev. Chil. Hist. Nat. 2012, 85, 161-169. [CrossRef]

51. Githiru, M.; Lens, L.; Adriaensen, F.; Mwang'ombe, J.; Matthysen, E. Using science to guide conservation: From landscape modelling to increased connectivity in the Taita Hills, SE Kenya. J. Nat. Conserv. 2011, 19, 263-268. [CrossRef]

52. Werlen, B. Global Sustainability, Cultural Perspectives and Challenges for Transdisciplinary Integrated Research; Springer: Berlin, Germany, 2015; ISBN 3319164775.

53. Benayas, J.M.R.; Newton, A.C.; Diaz, A.; Bullock, J.M. Enhancement of biodiversity and ecosystem services by ecological restoration: A meta-analysis. Science 2009, 325, 1121-1124. [CrossRef] [PubMed]

54. Bullock, J.M.; Aronson, J.; Newton, A.C.; Pywell, R.F.; Rey-Benayas, J.M. Restoration of ecosystem services and biodiversity: Conflicts and opportunities. Trends Ecol. Evol. 2011, 26, 541-549. [CrossRef]

55. Neis, B.; Schneider, D.C.; Felt, L.; Haedrich, R.L.; Fischer, J.; Hutchings, J.A. Fisheries assessment: What can be learned from interviewing resource users? Can. J. Fish. Aquat. Sci. 1999, 56, 1949-1963. [CrossRef]

56. Weng, Y.C. Contrasting visions of science in ecological restoration: Expert-lay dynamics between professional practitioners and volunteers. Geoforum 2015, 65, 134-145. [CrossRef]

57. Higgs, E. The Two Culture Problem: Ecological Restoration and the Integration of Knowledge. Restor. Ecol. 2005, 13, 159-164. [CrossRef]

(C) 2019 by the authors. Licensee MDPI, Basel, Switzerland. This article is an open access article distributed under the terms and conditions of the Creative Commons Attribution (CC BY) license (http:/ / creativecommons.org/licenses/by/4.0/). 